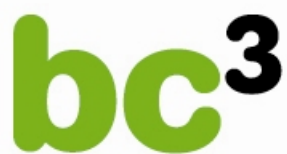

BASQUE CENTRE FOR CLIMATE CHANGE

Klima Aldaketa Ikergai

\title{
International Climate Finance and its Influence on Fairness and Policy
}

Karen Pittel and Dirk Rübbelke

$$
\text { June } 2011
$$

BC3 WORKING PAPER SERIES

2011-04 
The Basque Centre for Climate Change (BC3) is a Research Centre based in the Basque Country, which aims at contributing to long-term research on the causes and consequences of Climate Change in order to foster the creation of knowledge in this multidisciplinary science.

The BC3 promotes a highly-qualified team of researchers with the primary objective of achieving excellence in research, training and dissemination. The Scientific Plan of BC3 is led by the Scientific Director, Prof. Anil Markandya.

The core research avenues are:

- $\quad$ Adaptation to and the impacts of climate change

- $\quad$ Measures to mitigate the amount of climate change experienced

- $\quad$ International Dimensions of Climate Policy

- $\quad$ Developing and supporting research that informs climate policy in the Basque Country

See www.bc3research.org for further details.

The BC3 Working Paper Series is available on the internet at http://www.bc3research.org/working_papers/view.html

Enquiries (Regarding the BC3 Working Paper Series):

Roger Fouquet

Email: roger.fouquet@bc3research.org

The opinions expressed in this working paper do not necessarily reflect the position of Basque Centre for Climate Change (BC3) as a whole.

Note: If printed, please remember to print on both sides. Also, perhaps try two pages on one side. 


\title{
International Climate Finance and its Influence on Fairness and Policy
}

\author{
Karen Pittel ${ }^{*}$ \\ Dirk Rübbelke**
}

Besides costs and benefits, fairness aspects tend to influence negotiating parties' willingness to join an international agreement on climate change mitigation. Fairness is largely considered to improve the prospects of success of international negotiations and hence measures raising fairness perception might - in turn - help to bring about effective cooperative international climate change mitigation. We consider the influences present international support of climate policy in developing countries exerts on fairness perception and how this again might affect international negotiations. In doing so, we distinguish between fairness perception which is based on historical experiences and perception which is based on conjectures about opponents' intentions. By identifying beneficial components of current support schemes, lessons can be learnt for designing new schemes like the Green Climate Fund.

Keywords: adaptation, chicken game, climate policy, fairness, international agreements, mitigation, reciprocity, transfers

JEL Classification: F53, H87, Q54

Cite as: Pittel, K. and Rübbelke, D. (2011), International Climate Finance and its Influence on Fairness and Policy. BC3 Working Paper Series 2011-04. Basque Centre for Climate Change (BC3). Bilbao, Spain.

* Karen Pittel, Ifo Institute for Economic Research and University of Munich, Poschingerstrasse 5, 80802 Munich, Germany, email: pittel@ifo.de.

** Dirk T.G. Rübbelke, Basque Centre for Climate Change (BC3), Alameda Urquijo 4, 48008, Bilbao, Spain, and IKERBASQUE, Basque Foundation for Science, 48011, Bilbao, Spain, email: dirk.ruebbelke@bc3research.org. 


\section{Introduction}

Fairness plays a role in diverse international policy arenas addressing transnational market failures. In these arenas, voluntary coordination between individual states is necessary for attaining a Pareto optimal allocation, since there is no coercive international authority that can enforce efficiency generating measures. Prominent examples of such arenas are the fields of international trade (see, e.g. Stiglitz 2000, Suranovic 2000, Davidson, Matusz and Nelson 2006), and the provision of global public goods like climate protection (see, e.g. Albin 2003, Buchholz and Peters 2007, Tavoni et al. 2011) or the management of international public bads like financial instability (see, e.g. Wyplosz 1999, Gabriele, Boratav and Parikh 2000). Our interest is closely related to the field of sub-optimal low provision of global public goods, and we investigate how international finance may support the provision level of global public goods via influencing fairness perception in individual countries. More specifically, we consider the international support of developing countries in climate change mitigation and adaptation. ${ }^{1}$

International climate finance has recently experienced a strong push. At the $16^{\text {th }}$ Conference of Parties (COP) to the United Framework Convention on Climate Change (UNFCCC) in Cancun in 2010, it was pledged to mobilize $\$ 100$ billion in international climate financing annually by 2020. These public and private funds are dedicated to mitigation and adaptation projects in developing countries. Since it was also agreed that adaptation "must be addressed with the same priority as mitigation" (UNFCCC 2011), it is conceivable to assume that a large share of the $\$ 100$-billion pledge will be assigned to adaptation support. A significant share of new multilateral funding for adaptation is planned to flow through the Green Climate Fund, whose creation was also agreed upon in Cancun. Preparations for the Green Climate Fund are currently underway and intense debates about the appropriate design of strategies and involved mechanisms are taking place. The vision for long-term cooperative action with respect to global warming that was stipulated in Cancun is explicitly put on the basis of equity and of accordance with common but differentiated responsibilities and respective capabilities (UNFCCC 2011). ${ }^{2}$ Yet, there exist different equity and justice principles which

\footnotetext{
${ }^{1}$ While mitigation is a global public good, adaptation is in most cases a kind of 'private good' from the perspective of a whole country conducting adaptation, since the associated benefits tend to be mainly local or regional (Stern 2007: 406). Or as Barrett (2008: 254) puts it, "[i]n contrast to mitigation, the benefits of adaptation are excludable” from an individual country's point of view. Hence, international support of these two climate policy options (adaptation and mitigation) induces diverse effects of different degrees of publicness.

${ }^{2}$ Hepburn and Müller (2010) propose to implement a levy on international air passengers in order to raise funds for international adaptation finance and argue that it has the "equity benefit of focusing purely on (individual) responsibility and capability” (Hepburn and Müller 2010: 837).
} 
could be applied in global warming policy (see Kverndokk and Rose 2008) and internationally there is no unanimous agreement about the appropriate principle. According to Lange, Vogt and Ziegler (2007), who conducted an empirical analysis based on data from a world-wide survey of people involved in climate policy, the polluter-pays rule and the accompanying poor losers rule are the most widely accepted equity principles. Depending on whether an international climate policy or strategy serves an individual country's idea of equity or justice, this country will regard the respective policy or strategy as either fair or unfair. Fairness, in turn, tends to affect agents' conduct (see, e.g. Bolton 1991, Rabin 1993, 1998, Fehr and Gächter 2000 and Falk and Fischbacher 2006), but the channels, ways and degrees of its influence are ambiguous and highly disputed.

A large strand of the climate-policy related fairness literature deals with distributive fairness aspects involved in climate change mitigation policy. Ringius, Torvanger and Underdal (2002) investigate burden sharing proposals in international negotiations on climate change and discuss their distributive fairness properties. Different approaches for the design of burden sharing schemes, e.g. based on carbon intensity or historical responsibility concepts, reflect different social understandings of fairness and "[t]hese different perceptions of fairness are shaped to a large extent by the highly disparate positions that countries occupy in the global hierarchy of economic and political power” (Parks and Roberts 2008: 624). Rive, Torvanger and Fuglestvedt (2006) investigate historical responsibility for global warming as a criterion for the distribution of mitigation requirements in future climate agreements and they identify fairness principles as a factor - in turn - influencing the design of historical responsibility schemes. As Rabin (1993: 1284) remarks, although agents' decisions are influenced by fairness considerations, people tend not to "be as willing to sacrifice a great amount of money to maintain fairness as they would be with small amounts of money”. ${ }^{3}$ Such a potential conflict of objectives between fairness and self-interest has also been referred to by Hammar and Jagers (2007), who investigate distributive fairness aspects of carbon taxation. Hence, it is ambiguous to which extent fairness aspects indeed influence the behavior of policymakers in international climate policy, since material wellbeing of countries is affected to a big extent in this policy arena. Lange et al. (2010) argue that although equity arguments may be perceived as being used out of fairness considerations,

\footnotetext{
${ }^{3}$ Akerlof (1979: 233) considers the trade-off between fairness and profits in the labour market and points out that "while wage policy cannot totally disregard markets, because some wage policies would be too costly for the firm to pursue, there is nevertheless a range of possible standard business practices, that, once expected to be followed and considered to be ethically correct, will prove themselves too costly to violate.”
} 
equity principles in international climate negotiations are mostly correlated with the selfinterest of the negotiating parties. However, a recent study by Carlsson et al. (2011) on ingroup bias, i.e. on whether preferences for effort-sharing rules for reducing carbon dioxide emissions are based only on the rules per se or whether they are confounded with personal preferences for individual countries, finds that ingroup bias is less of a problem.

Besides such studies on fairness of effort sharing in climate change mitigation, there has been research on fairness related to other aspects like fairness in adaptation and procedural fairness. Principles for fair adaptation to climate change have been discussed, e.g. Paavola and Adger (2006) and Grasso (2007). Grasso (2010) develops a framework of procedural and distributive justice tailored to international funding of adaptation to climate change. Rübbelke (2011) considers procedural and distributive aspects of fairness involved in international mitigation and adaptation policy and investigates in a game-theoretic setting the potential role of fairness for the attainment of an effective international agreement on climate protection. Mainly variations of historical fairness perceptions via increases in international adaptation support are in the focus of his study.

The present study neither discusses fairness of effort sharing schemes in climate change mitigation, nor does it generate a framework for 'fair' adaptation to climate change. Instead, our focus is on the subarea of international support of climate policy: we analyze the potential role of present international support of mitigation and adaptation projects in developing countries in raising fairness perception. We investigate how induced fairness effects might in turn influence international negotiations on climate change mitigation. In contrast to Rübbelke (2011), we explicitly consider changes also in the level of intention driven fairness, i.e. the fairness assigned to other agents on the basis of both these agents' motives and choices (see Rabin 1993 for such intentionality in attitudes about fairness), in a game-theoretic setting and not only modifications in consequence driven fairness perception, i.e. fairness perception based on the (expected) consequences of agents' behavior in the past. This allows a more precise elaboration of the interrelations between the different applied fairness concepts (intention and consequence driven fairness). Furthermore, we consider and identify different channels for changing fairness perception in the current international support schemes.

From this analysis we obtain insights about the adequate design of international support of developing countries' climate policy (related to both mitigation of and adaptation to climate change) for enhancing fairness perception and for bringing about more effective cooperative 
international climate change mitigation. From these results, lessons can be learnt for the appropriate design of international funds, like the Green Climate Fund.

\section{Fairness Perception in Climate Policy}

The present rules of procedures at the COP to the UNFCCC stipulate that decisions are taken by consensus. Yet, as Müller (2010: 23) points out concerning the failure of the COP in Copenhagen in 2009, the problem "was what was seen to be the blatant disregard for these procedures and the resulting (strongly felt) disrespect that were at the root of the problem.” Several developing countries perceived some form of exclusion during the Copenhagen negotiation processes which turned out to raise the distrust these countries hold with respect to industrialized countries in international climate policy. Put it differently, they felt treated in an unfair way.

As we will discuss, the influence of the perception of unfairness on international climate negotiations tends to be adverse. In doing so we distinguish between 1) intention driven fairness perception and 2) consequence driven fairness perception (see Rübbelke 2011). Thereafter, we will demonstrate how international support of climate policy in developing countries may help to improve fairness perception.

The concepts of intention and consequence driven fairness we employ, are not fully congruent with the frequently discussed concepts of procedural and distributive fairness respectively. The literature on distributive and procedural fairness largely approaches the idea of fairness in a normative way weighing up different fairness principles, or as Kverndokk and Rose (2008: 139) explain, there are these two ways to justify why an action is good or bad from an ethical standpoint, i.e. ethically not only consequences matter, but also the process by which outcomes are reached. According to Grasso (2010: 75), procedural fairness of international adaptation funding regimes would require that all relevant parties are involved, for example. Different distributive fairness principles are outlined by Ringius, Torvanger and Underdal (2002: 4-11). The normative analysis might help to assign 'fairness' to specific procedures, sharing rules or outcomes. In contrast, intention driven fairness perception and consequence driven fairness perception concepts as used in this study just refer to the perceptions of fairness which are potentially held by policymakers in the negotiation process, but there is no attempt to justify any procedure, state or outcome from a normative point of view. Instead, the outcomes are negotiated in a decentralized way, but decision making is 
influenced by fairness perceptions held by individual policymakers. We do not evaluate whether the perceived (un-)fairness is justifiable from an ethic point of view.

Intention driven fairness perception depends on beliefs about the other negotiating agents' intentions in the present negotiation process or in current international climate policy in general. Already Geanakoplos, Pearce and Stacchetti (1989) stressed the role of beliefs in game-theoretical contexts and in their framework, agents' payoffs depend on both players' beliefs and their actions. Based on this approach, Rabin (1993) developed the concept of kindness functions, which measure how kind an agent is to another. Unkind behavior of opponent parties generates fairness cost for a negotiating agent, while mutually kind behavior generates fairness benefits for the considered agent. By including fairness benefits or unfairness cost affecting an agent's total payoffs (which in turn include both material and fairness payoffs), the perceived kindness of other agents influences a negotiating agent's behavior. Hence, negotiating parties’ payoffs depend on both players' beliefs (about other agents' kindness) and their actions. Agents may prefer to sacrifice some of their material well-being for fairness reasons, i.e. either for helping those who are kind to them or for punishing those who are unkind (Rabin 1997: 1). This is in line with Lange, Vogt and Ziegler (2007: 546) who point out with respect to international climate change mitigation: "In a world where no single party will provide the common good in sufficient quantity and no institution exists to enforce cooperation, an agreement will only be accepted by the parties if it is assessed to be beneficial in terms of costs and benefits and if it is perceived to be fair". Consequently, both economic efficiency and fairness are to be considered as prerequisites for attaining an effective international agreement on climate change.

Yet, as Falk and Fischbacher (2006: 309) point out, "[k]indness comprises both the consequences as well as the intention of action”. So, consequences of activities executed by other agents before the present negotiations take place could also influence fairness perception, i.e. consequence driven (or historical) fairness perception, during the negotiations. Müller, Höhne and Ellermann (2009) argue that a fair burden sharing would have to be based on a combination of historical responsibility shares and some differentiated index of capability. Hence, responsibility for combating climate change is mainly assigned to the industrialized world whose greenhouse gas (GHG) emissions have been a negative sideeffect of their economic development yielding prosperity (which makes them, in turn, more capable of combating global warming) and these emissions have predominantly caused the current global warming threat. Yet, as industrialized countries may argue, past economic 
development in industrialized countries has brought about technical progress from which also developing countries benefit and which now supports poor countries' development. Consequently, taking into account different layers and aspects of the complex global warming problem, a ubiquitous principle ascertaining universal fairness does not exist in international climate policy. Nevertheless, negotiating parties hold their own views on fairness and these tend to influence their conduct in the negotiation processes.

\section{Influence of Fairness Effects of Adaptation Support on International Negotiations}

It has often been stressed in the literature on international negotiations that negotiations on climate change mitigation can best be described as a chicken game situation (see, e.g. Carraro and Siniscalco 1993). Also, the game of chicken is taken to be "perhaps the ideal game for contrasting fairness and self-interested preferences” (Camerer 1997: 171). In the following, we will show in a chicken game setting how changes in negotiation pay-offs due to the consideration of intention and consequence fairness can affect the equilibrium strategies chosen by the negotiating parties. We will specifically focus on the potential of reducing unfairness to increase the likelihood of a cooperative outcome.

According to Rabin (1993), the expected utility of an agent depends on his own strategy, on his beliefs about the strategy of the other agent and his believes about what the other agent believes about his strategies. To simplify the presentation, we follow, in a two-player chicken setting, a depiction of intention driven fairness adjustment proposed by Camerer and Thaler (2003). In contrast to their paper however, we express pay-offs in a more general way. Furthermore, we include consequence driven or historical fairness adjustment terms in order to illustrate possible interrelations between intention and consequence driven fairness aspects. In the game depicted in Figure 1, the two negotiating agents face the choice between participating or not participating in an international agreement on climate change mitigation. We assume one agent to be a rich industrialized region (subscript $R$ ) and the other to be a poor developing region (subscript $P$ ). The net material pay-offs of each region (benefits of climate policy minus the costs of taking action) are given by $A_{i}, B_{i}, C_{i}$ and $D_{i}, i=R, P$. For a chicken game scenario to arise when no fairness are considered the following relations have to hold: $0<A_{R}<C_{R}, B_{R}>D_{R}>A_{R}, 0<A_{P}<B_{P}, C_{P}>D_{P}>A_{P}$. 
Besides the material pay-offs we additionally consider the adjustments of pay-offs that arise from the feeling of being treated fairly or unfairly. $\alpha_{i}^{I}>0$ reflects the intensity of intention driven fairness in country $i$ while $\alpha_{i}^{H}>0$ gives the intensity of consequence driven or historical fairness. An increase in fairness induces a decline of the respective $\alpha$. For simplicity we assume that intention and consequence driven fairness adjustments can be considered separately that is, they enter pay-offs additively.

\begin{tabular}{|c|c|c|}
\hline P's strategy & no participation & participation \\
\hline no participation & $A_{R}-m^{H}\left(\alpha_{R}^{H}\right){ }^{A_{P}}$ & $\begin{array}{l}B_{P}-u^{I}\left(\alpha_{P}^{I}\right)-u^{H}\left(\alpha_{P}^{H}\right) \\
B_{R}-u^{H}\left(\alpha_{R}^{H}\right)\end{array}$ \\
\hline participation & $C_{R}-u^{I}\left(\alpha_{R}^{I}\right) \quad{ }$ & $\begin{array}{l}\quad D_{P}+m^{I}\left(\alpha_{P}^{I}\right)-m^{H}\left(\alpha_{P}^{H}\right) \\
D_{R}+m^{I}\left(\alpha_{R}^{I}\right)\end{array}$ \\
\hline
\end{tabular}

Figure 1: Negotiations on Climate Change Mitigation with Fairness-Adjusted Payoffs.

\subsection{Fairness Adjustments}

For each region, the impact of fairness adjustment on pay-offs depends on whether the region is developing or industrialized and on whether or not the other region participates in international mitigation. Please note that in Figure 1 we only depict net fairness adjustments for clarity of presentation. For the developing region this implies, for example, that fairness adjustments affect the pay-off matrix only in case of participation while, fairness adjustments in case of non-participation are set equal to zero.

\section{Developing region}

Overall fairness adjustments in the case of developing countries are given by

- $F_{P}^{U}=-u^{I}\left(\alpha_{P}^{I}\right)-u^{H}\left(\alpha_{P}^{H}\right)$ if the developing region unilaterally participates in the climate agreement. $F_{P}^{U}$ can be interpreted as the discomfort of $P$ from having been and still being treated in an unfair way. 
- $\quad F_{P}^{M}=m^{I}\left(\alpha_{P}^{I}\right)-m^{H}\left(\alpha_{P}^{H}\right)$ in case of mutual participation and contribution to climate protection.

$F_{P}^{U}$ and $F_{P}^{M}$ both contain two components:

\section{Intention driven fairness adjustment component}

For the developing region, this component is reflected by $-u^{I}\left(\alpha_{P}^{I}\right)<0$ in the situation of unilateral cooperation and $m^{I}\left(\alpha_{P}^{I}\right)>0$ in case of mutual cooperation. It is assumed following Camerer and Thaler (2003) - that the negative fairness adjustment ('negative reciprocity') arising in case of non-cooperation of region $R$ is stronger than the positive fairness effect ('positive reciprocity') in case of mutual participation $\left(u^{I}\left(\alpha_{P}^{I}\right)<m^{I}\left(\alpha_{P}^{I}\right)\right)$. We furthermore assume that a rise in intention driven fairness (decline of $\alpha_{P}^{I}$ ) as perceived by developing countries induces an increase in cooperative fairness benefits and mitigates the unfairness cost in case of unilateral participation, since the opponent, i.e. the industrialized world, is generally perceived to become more kind (i.e. $\frac{d u^{I}}{d \alpha_{P}^{I}}>0$ and $\frac{d m^{I}}{d \alpha_{P}^{I}}<$ $0)$.

\section{Consequence driven fairness adjustment component}

As Messner et al. (2010) remark, "in accordance with the polluter-pays principle, the industrialized countries have a particular responsibility to cut their greenhouse gas emissions due to their high cumulative emissions in the past”. Developing countries not only share this view in principle but even tend to the poor losers principle allowing for exemption due to low GDP levels (Lange, Vogt and Ziegler 2007). Therefore they often perceive their own contributions to mitigation as unfair per se. In line with this, Messner et al. (2010) conclude that unless the industrialized countries act according to their particular responsibility, "hardly any global climate treaty will ever be achieved." In line with this reasoning, we assume that developing countries' payoffs are adjusted negatively whenever they participate in international mitigation agreements. Additionally, developing countries regard a situation in which industrialized countries do not participate while developing countries do to be even more unfair than a situation of mutual participation $\left(m^{H}\left(\alpha_{P}^{H}\right)>\right.$ $u^{H}\left(\alpha_{P}^{H}\right)>0$ with $\left.\frac{d u^{H}}{d \alpha_{P}^{H}}, \frac{d m^{H}}{d \alpha_{P}^{H}}>0\right)$.

It becomes immediately apparent, that the consequence driven fairness adjustment reinforces the tendency for negative reciprocity in the case of unilateral participation of the 
developing region, while it mitigates positive reciprocity in the case of mutual cooperation.

\section{Industrialized region}

For the industrialized region, we equivalently consider intention and consequence driven fairness by separate terms.

\section{Intention driven fairness adjustment component}

As the perception of intention driven fairness solely depends on whether or not the other agent participates in the agreement, we assume that the same mechanisms work in the industrialized and developing world. That is, we assume $u^{I}\left(\alpha_{R}^{I}\right)<m^{I}\left(\alpha_{R}^{I}\right)$ to hold.

\section{Consequence driven fairness adjustment component}

Due to high past emission levels in the industrialized world it is conceivable that industrialized countries hold some sense of guilt and they themselves might consider their non-participation in international climate change mitigation as unfair. Therefore, we include consequence driven fairness terms, $m^{H}\left(\alpha_{R}^{H}\right)$ and $u^{H}\left(\alpha_{R}^{H}\right)$, in the payoff functions of the industrialized region when it defects, i.e. plays 'no participation'. ${ }^{4}$ These terms reduce the attractiveness of 'no participation' from this region's point of view. If the industrialized world conducted policies that help to reduce their feeling of guilt, i.e. that reduce the consequences of past unfairness, $m^{H}\left(\alpha_{R}^{H}\right)$ and $u^{H}\left(\alpha_{R}^{H}\right)$ would decline, which in turn - raises the attractiveness of 'no participation', i.e. the industrialized region is more likely to take a free ride in international climate change mitigation. Regarding the level guilt perceived, it seems straightforward to assume that unilaterally playing 'no participation' is associated with higher unfairness adjustment than mutual defection $\left(m^{H}\left(\alpha_{R}^{H}\right)<u^{H}\left(\alpha_{R}^{H}\right)\right)$.

From Figure 1, we can easily see that we still face a chicken game if the following relations hold for the industrialized region $u^{I}\left(\alpha_{R}^{I}\right)-m^{H}\left(\alpha_{R}^{H}\right)<C_{R}-A_{R}$ and $u^{H}\left(\alpha_{R}^{H}\right)+m^{I}\left(\alpha_{R}^{I}\right)<$ $B_{R}-D_{R}$ and for the developing region $u^{I}\left(\alpha_{P}^{I}\right)+u^{H}\left(\alpha_{P}^{H}\right)<B_{P}-A_{P}$ and $m^{I}\left(\alpha_{P}^{I}\right)-$

\footnotetext{
${ }^{4}$ The 'veil of uncertainty' also plays a role in negotiations of regimes as Young (1989) discusses on the basis of the earlier works by Rawls (1971) and Brennan and Buchanan (1985). In line with this, we could argue that industrialized countries might - due to the long-term scope and generality of an international climate regime be uncertain about the impact of different alternatives on their own future well-being. Then they "tend to agree on arrangements that might be called 'fair'” and the "uncertainty introduced in any choice among rules or institutions serves the salutary function of making potential agreement more rather than less likely” (Brennan and Buchanan 1985).
} 
$m^{H}\left(\alpha_{P}^{H}\right)<C_{P}-D_{P}$. In this case we face a chicken game with and without fairness adjustments. Thus, in both games the Nash equilibria with pure strategies are (no participation, participation) and (participation, no participation).

As long as there are uncertainties prevailing with respect to the participation of other countries, mixed strategies become relevant. In this case, policymakers of the individual countries estimate probabilities about the counterparts' behaviour and make their decisions based on these estimates and the corresponding expected payoffs. Country group $R$ estimates the likelihoods of country group $P$ 's participation $\left(p_{P}\right)$ and non-participation $\left(1-p_{P}\right)-$ and conversely country group $P$ estimates respective likelihoods for country group $R$ ( $p_{R}$ and $\left.1-p_{R}\right)$. For the mixed strategy in the game described by Figure 1, the developing region is indifferent between playing 'participation' and ‘no participation' if

$$
p_{R}^{*}=\left(1+\frac{C_{P}-D_{P}-m^{I}\left(\alpha_{P}^{I}\right)+m\left(\alpha_{P}^{H}\right)}{B_{P}-A_{P}-u^{I}\left(\alpha_{P}^{I}\right)-u^{H}\left(\alpha_{P}^{H}\right)}\right)^{-1}
$$

holds for the industrialized region's probability of participation. If $P$ conjectures that the rich region plays 'participation' with a probability exceeding this threshold, then it will play 'no participation' in the chicken game setting. Hence, the higher the threshold in (1), the higher is the probability that the developing region will participate in international mitigation efforts.

Equivalently, the industrialized region is indifferent between its two strategies if

$$
p_{P}^{*}=\left(1+\frac{B_{R}-D_{R}-m^{I}\left(\alpha_{R}^{I}\right)-u^{H}\left(\alpha_{R}^{H}\right)}{C_{R}-A_{R}-u^{I}\left(\alpha_{R}^{I}\right)+m^{H}\left(\alpha_{R}^{H}\right)}\right)^{-1}
$$

From (1) and (2) it can easily be seen that intention driven fairness affects the threshold probabilities of the industrialized and the developing region in the same way - as was to be expected as intention driven effects arise symmetrically in the two regions. With respect to consequence driven fairness, however, its effects on $p_{P}^{*}$ and $p_{R}^{*}$ are exactly opposite. Negative fairness effects arise for the industrialized region (due to the feeling of guilt) if the region does not participate while they arise for the developing country (due to resentment) in case that the region participates.

The interesting question that follows from (1) and (2) is now how fairness considerations affect the likelihood of cooperative behavior in the two regions. Obviously, the two regions will react qualitatively in the same way to changes of intention driven fairness perception while changes in consequence driven fairness perception will induce contrary reactions. In 
order to simplify the presentation we will in the following focus on the developing region's reactions while bearing the corresponding reactions of the industrialized region in mind.

\subsection{Comparative Statics of Fairness Perception}

To analyze the influence of intention and consequence driven fairness on the likelihood of cooperative behavior of the developing region, we derive

$$
\begin{aligned}
& -\frac{\partial p_{R}^{*}}{\partial \alpha_{P}^{H}}=-\left(p_{R}^{*}\right)^{-2} \frac{\left(C_{P}-D_{P}-m^{I}\left(\alpha_{P}^{I}\right)+m^{H}\left(\alpha_{P}^{H}\right)\right) \frac{d u^{H}}{d \alpha_{P}^{H}}+\left(B_{P}-A_{P}-u^{I}\left(\alpha_{P}^{I}\right)-u^{H}\left(\alpha_{P}^{H}\right)\right) \frac{d m^{H}}{d \alpha_{P}^{H}}}{\left(B_{P}-A_{P}-u^{I}\left(\alpha_{P}^{I}\right)-u^{H}\left(\alpha_{P}^{H}\right)\right)^{2}}>0 \\
& -\frac{\partial p_{R}^{*}}{\partial \alpha_{P}^{I}}=-\left(p_{R}^{*}\right)^{-2} \frac{\left(C_{P}-D_{P}-m^{I}\left(\alpha_{P}^{I}\right)+m^{H}\left(\alpha_{P}^{H}\right)\right) \frac{d u^{I}}{d \alpha_{P}^{I}}\left(B_{P}-A_{P}-u^{I}\left(\alpha_{P}^{I}\right)-u^{H}\left(\alpha_{P}^{H}\right)\right) \frac{d m^{I}}{d \alpha_{P}^{I}}}{\left(B_{P}-A_{P}-u^{I}\left(\alpha_{P}^{I}\right)-u^{H}\left(\alpha_{P}^{H}\right)\right)^{2}}>0 .
\end{aligned}
$$

where the terms in brackets in the fractions on the right-hand sides are positive in case of a chicken game.

With respect to an increase in historical or consequence driven fairness as perceived by the developing region (decrease in $\alpha_{P}^{H}$ ), it can easily be seen that cooperation of the this region becomes more likely since the threshold probability rises. This is straightforward as the payoffs which the developing region obtains when it participates, increase following a decrease in perceived historical unfairness.

On as first glance, the effects of a change in intention driven fairness look slightly more complex as the direction of fairness adjustment depends on the participation decision of the other region: unfairness costs arise in the case of unilateral participation while fairness benefits follow from mutual cooperation. As, however, a rise in intention driven fairness reduces unfairness costs while simultaneously fairness benefits from mutual cooperation increase, the likelihood of cooperation also rises in a chicken game following an augmentation of intention driven fairness.

\subsection{The General Role of Consequence Driven Fairness Perception}

So far, we have assumed that international negotiations on climate change mitigation take the form of a chicken game. We justified this assumption by arguing that this approach is followed quite often in the literature. Yet, some authors also employ, for example, a prisoners' dilemma (PD) game in which 'no participation' is the dominant strategy. In order to integrate these dissenting views about the game's pay-off structure and thus be able 
analyze the influence of fairness perception more generally, we now abandon our initial assumption of a chicken game situation and also consider PD and stag hunt games.

A PD game differs from the chicken setting with respect to the ratio between payoffs of unilateral participation and mutual defection. While

$$
A_{P}<B_{P}-u^{I}\left(\alpha_{P}^{I}\right)-u^{H}\left(\alpha_{P}^{H}\right)
$$

holds in the chicken situation, in the PD setting

$$
A_{P}>B_{P}-u^{I}\left(\alpha_{P}^{I}\right)-u^{H}\left(\alpha_{P}^{H}\right)
$$

holds instead. It is apparent that the level of consequence driven or historical fairness adjustment could make the difference between both game situations. ${ }^{5} \mathrm{~A}$ decline in $\alpha_{P}^{H}$ would raise the right-hand side of (6) and the situation may change so that we obtain (5), i.e. the dominance of the 'no participation' strategy may break down such that cooperative behavior becomes more likely. Consequently, in both the PD and the chicken game setting, a rise in consequence driven fairness tends to improve the prospect of cooperative behavior of the developing region.

However, the most positive effect could occur in a situation where very strong intention driven fairness adjustment takes place, i.e. where $\alpha_{i}^{I}$ is very large. In such a situation the game may turn into a coordination game of the stag-hunt type, where the Nash equilibria with pure strategies are (no participation, no participation) and (participation, participation) which is an outcome of the (negative and positive) reciprocity effects of intention driven fairness adjustment. From the developing region's perspective, (6) and

$$
C_{P}<D_{P}+m^{I}\left(\alpha_{P}^{I}\right)-m^{H}\left(\alpha_{P}^{H}\right)
$$

hold in the stag-hunt case. Given this pay-off structure, a rise in consequence driven fairness might induce the dominance of 'participation' strategy. A decline in $\alpha_{P}^{H}$ would raise positive reciprocity in case of mutual cooperation but mitigate negative reciprocity in case of unilateral cooperation. It could happen that the ratio between both sides of (7) reverses, which implies that 'participation' becomes the dominant strategy. Hence, while intention driven fairness adjustment tends to make both, mutual non-cooperation and mutual cooperation, more likely, consequence driven fairness adjustment tends to reduce the likelihood of cooperation when past activities of opponents (and related consequences) are considered to

\footnotetext{
${ }^{5}$ For a discussion of transitions in structures of games depicting negotiations on climate change, see also Pittel and Rübbelke (2011).
} 
be unfair but tends to augment the likelihood of cooperation when consequence driven fairness is increased.

\section{Support of Climate Policy in Developing Countries}

Industrialized countries could positively influence fairness perception in developing countries by supporting them in climate policy. The improved fairness perception in poor countries could in turn improve the prospects of success of international negotiations on climate change mitigation. Yet, the support might also reduce unfairness cost in the industrialized world, which tends to exert a negative influence on industrialized countries' readiness to contribute to international mitigation. Let us distinguish between different kinds of support and between influences on intention driven fairness on the one hand side and consequence driven fairness on the other hand side.

\subsection{Support of Mitigation}

Industrialized countries support developing countries in climate policy by providing conditional transfers for climate change mitigation in these countries. The Global Environmental Facility (GEF) serves as the financial mechanism under the UNFCCC which collects funds from industrialized countries and channels these towards climate protection projects in the developing world. Next, it is considered how these transfers might improve fairness perceived in the developing world, but also reasons for moral concerns brought about with respect to this support are regarded.

Industrialized countries' subsidization of mitigation in the developing world might be interpreted as a means to improve intention driven fairness (which is reflected by a decline of $\left.\alpha_{P}^{I}\right),{ }^{6}$ since it signals - not unlike industrialized countries' commitments to domestic mitigation efforts under an international protocol - a preparedness of industrialized countries to invest in climate protection. Put it differently, the ostensive sense of responsibility of the industrialized world tends to raise the level of kindness the developing world assigns to the rich countries. Unfortunately, the induced benefits of mitigation support will arise only in distant future, which is due to the thermal inertia of the global system. Furthermore, the prevailing self-interest of industrialized countries in the cost-effective 'purchase of

\footnotetext{
${ }^{6}$ The degree of fairness improvement depends on the level of the subsidy rate and the induced benefits in the industrialized and developing world. On the influence of the subsidy rate level on the welfare level in the supported developing country see Rive and Rübbelke (2010) who consider conditional transfers channeled through the Clean Development Mechanism.
} 
abatement' in developing countries via mitigation support might impair the credibility of such activities to be based on kindness (although the abatement support is not credited for potential commitments of industrialized countries in an international protocol, as would be the case with respect to efforts associated with the Clean Development Mechanism). Since - due to the public good property of climate change mitigation and the lower mitigation cost in the developing world - industrialized countries also benefit from mitigation in developing countries, poor countries might not consider the mitigation support as a signal of rich countries for playing 'fair'. And unfair background conditions for interaction between poor and rich countries may constitute moral concerns, as they influence the conditions for granting and accepting international transfers dedicated to the support of mitigation (see Eyckmans and Kverndokk 2010 who allude to the potential role of unfair background conditions in the context of pollution permits trading).

Next, we turn to consequence driven fairness aspects (influencing the level of $\alpha_{P}^{H}$ ) induced by respective international transfers. In doing so, let us distinguish between two major strands of mitigation policies, i.e. between GHG abatement and carbon sequestration, and between two different aspects, i.e. between compensating for past emissions and compensating for damage cost caused by past emissions.

- Compensating for past emissions: Past emissions cannot be removed anymore by abatement activities and consequently, negative consequences of past GHG emissions are unaffected by a rise in abatement efforts. In contrast, mitigation activities in the shape of carbon sequestration (e.g. by means of reforestation projects) would indeed reduce the negative consequences of past emissions since a part of the latter is removed by the carbon uptake by forests. Hence, while the commitment to abatement support tends to affect only intention driven fairness perception in the developing world, carbon sequestration support would - in principle - also serve consequence driven fairness improvement (and may hence reduce the level of $\alpha_{P}^{H}$ ).

- Compensating for damage cost caused by past emissions: If we take into account that mitigation activities in the developing world are regularly associated with the generation of significant domestic ancillary benefits in the mitigation project hosting country (e.g. improved air pollution, preservation of water availability, prevention of desertification; see Pittel and Rübbelke 2008), these benefits could be interpreted as a kind of compensation payment for climate change damage mainly caused by the industrialized world. Hence, 
consequence driven fairness aspects might be affected - via ancillary benefits - by both abatement and sequestration support policies (reducing the level of $\alpha_{P}^{H}$ ).

We are aware of the fact that these aspects only gather a small array of possible views on fairness. Plenty of further (un-)fairness arguments and aspects might be cited in the context of international mitigation support provided by the UNFCCC's financial mechanism. However, the selected array allowed for an ostensive illustration of the general differences between consequence driven and intention driven fairness influences exerted by the international support.

Above all, it seems to be unlikely that negotiators in international climate policy will consider and evaluate all particular fairness influences and aspects in detail in order to derive ubiquitous equity principles they intend to support. Instead, their beliefs about equity will probably be based on more narrow views which exclude several aspects. As Breton and Dalmazzone (2002: 46) point out: "It is costly to ascertain objectively the different states of the world. To minimize these costs, individuals form beliefs over those states of the world that are of relevance to them. These beliefs then serve as a basis for making decisions.” And as Akerlof and Dickens (1982: 307) explain, agents can manipulate their own beliefs by selecting sources of information, which tend to confirm desired beliefs. This might explain why Lange et al. (2010) find that perceived support of different equity rules is generally consistent with economic self-interest. Negotiators in international climate policy tend to a big extent to advocate those equity principles which bring about the highest benefit for their country and they select their beliefs about equity and justice accordingly. Hence, it is idle to search for the universal fairness principle from a normative perspective, but in international negotiations it might make more sense to seek a consensus about equity rules between negotiators, which might - however - be strongly affected by self-interests.

Implicitly, such a consensus had been found in the past, when the main responsibility for mitigation had been assigned to the industrialized world. According to Article 4.3 of the UNFCCC, developed countries shall provide new and additional financial resources and transfer of technology needed by developing countries to meet the agreed full incremental costs of measures undertaken by developing countries in favor of the global environment. And as Baron (2006: 137-138) remarks, the negotiations leading to the Kyoto Protocol "have focused largely on the problem of fairness in allocating the burden among nations, with major issues concerning the balance of prior causation and ability to pay, and the extent to which countries can fulfill their obligations by paying for emission reductions in other countries.” 
Hence, international mitigation support may be seen by developing countries as a norm which was agreed upon in the past, and a deviation from it would be considered to be unfair. However, since the time when the UNFCCC was agreed, there have been major shifts in the GHG emission patterns internationally and new consensus about an appropriate equity principle has to be found adequately reflecting individual negotiating parties’ present views. ${ }^{7}$

\subsection{Support of Adaptation}

Adaptation support can also influence both the intention driven fairness (via a modification in the level of $\alpha_{P}^{I}$ ) and the consequence driven fairness (via a change in $\alpha_{P}^{H}$ ) adjustment. Adaptation activities preventing climate change damage in the developing world tend to raise consequence driven fairness perception. However, additional to these effects, the procedures for granting adaptation support might also influence intention driven fairness perception. Let us illustrate this by means of two examples:

\section{Global benefit orientation vs. no predefinition of the nature of benefits}

One track used by the GEF to provide adaptation support is the Strategic Priority "Piloting an Operational Approach to Adaptation” (SPA), which has been a part of the GEF Trust Fund. ${ }^{8}$ These funds were granted with global benefit orientation, i.e. developing and industrialized countries benefited from the induced adaptation activities. The transfers will help to prevent damage in poor countries caused by past emissions (which stem mainly from industrialized countries) and therefore may reconstitute some of the consequence driven fairness perceived in developing countries (i.e. they will cause a decrease in $\alpha_{P}^{H}$ ). Such prevention of damage in poor countries could also be generated by means of adaptation support not mainly aiming at global benefits, i.e. where the nature of benefits is not predefined. Consequently, both the global benefit oriented support as well as the support without global benefit focus, improve consequence driven fairness perception (and therefore decrease the level of $\alpha_{P}^{H}$ ).

However, support with global benefit orientation may evoke the impression that industrialized countries provide the support only because they have themselves an interest in induced adaptation activities and benefits. Therefore it exhibits some similarities to mitigation support. If the industrialized countries would instead abstain from the requirement

\footnotetext{
${ }^{7}$ As Müller (2001: 285-286) states, "the general architecture of the regime under the UNFCCC should not involve fixing legally binding distribution formulae for all eternity [...]. Like everything in the world, moral contexts are likely to change and what is fair in the present state of affairs may well be unfair under the as yet unknown - and even unforeseen - circumstances in fifty, one hundred, or a thousand years time."

${ }^{8}$ By September 2009, all SPA funding had been allocated.
} 
that supported adaptation projects should produce global benefits, this would generate the signal that the industrialized world is willing to help the poor countries regardless of own advantages, which is in turn a stronger signal for the willingness to play fair in international climate policy, ${ }^{9}$ i.e. intention driven fairness perceived in developing countries is raised (and thus the level of $\alpha_{P}^{I}$ alters). Or as Kydd (2000: 326) puts it: "Trust is conceived of as a belief that the other side is likely to be trustworthy and will therefore want to reciprocate cooperation rather than exploit it. Costly signals serve to separate the trustworthy types from the untrustworthy types; trustworthy types will send them, untrustworthy types will find them too risky to send". ${ }^{10}$ This implies that the high net-cost option of supporting adaptation projects producing only local benefits in the developing world, may amplify trust of the poor countries in a better way than the support of adaptation producing global utility which also benefits the industrialized world and thereby decreases its net cost.

Indeed, the other GEF-managed adaptation funds, i.e. the Least Developed Countries Fund (LDCF) and the Special Climate Change Fund (SCCF), are not managed with global benefit orientation. This is not only advantageous from an intention driven fairness perspective, but it is also more operational, since the benefits of most adaptation activities are largely local or regional (and not global).

\section{Participation of developing countries in the management of support mechanisms}

A positive effect on intention driven fairness-perception could be generated by organizing the international adaptation support in a way that allows for strong participation of developing countries in the management of support mechanisms. A strong participation will raise the confidence of developing countries that funds are disbursed in a way that they consider to be most beneficial for themselves and which, therefore, apparently - from the developing countries' policymakers' point of view - compensates them for (perceived) unfairness to the largest extent. Consequently, $\alpha_{P}^{H}$ tends to shrink, but also intention driven fairness is affected, since a more equitable approach in individual areas of international climate policy may also signal kind intentions of the industrialized world in negotiations on mitigation (i.e. which is reflected by a decrease in $\alpha_{P}^{I}$ ).

\footnotetext{
${ }^{9}$ As Paavola and Adger (2005: 360) state, “[w]hen agents have plural motivations - of which self-centred welfare maximisation is but one example - and their ability to detect the motivations of other agents is limited, then the act of signalling intentions becomes a means to elicit reciprocal behaviour.”

${ }^{10}$ Also see Parks and Roberts (2008) for this line of reasoning.
} 
A strong participation is destined, for example, with respect to the management of the Adaptation Fund (AF) which falls under the framework of the Kyoto Protocol and is managed and supervised by a special Adaptation Fund Board. ${ }^{11}$ Developing countries hold the overall majority of seats in the AF Board. In contrast, the GEF-lead management of adaptation funds (as in the case of LDCF and SCCF) is considered with scepticism in many developing countries, because the GEF's governance and agenda is regarded as dominated by the industrialized world (see, e.g., Najam, Huq and Sokona 2003: 225). The role of developing countries with respect to the Green Climate Fund (GCF), whose establishment had been decided at the COP in Cancun and which will become a major international mechanism for adaptation and mitigation support, is currently intensively discussed (see, e.g. Bird, Brown and Schalatek 2011). The GCF Board, which will govern the Fund, will comprise an equal number of members from industrialized and developing countries (UNFCCC 2011).

Yet, given significant governance problems in several developing countries, some of the delegated climate negotiators' of these developing countries may not agree that those adaptation options are most beneficial which effectively generate the highest climate change damage cost reduction. Instead they may pursue strategies maximizing their own personal wellbeing and not the welfare of their entire country. Hence, a strong participation of developing countries in the management of international adaptation funds does not guarantee a maximal positive effect of the disbursement of adaptation funds on consequence driven fairness perception within developing countries, although it looks attractive from intention driven fairness perspective.

\section{Conclusions}

There is much ambiguity with respect to fairness, equity and justice dimensions of international climate policy. What an agent in international negotiations "regards as a fair bargain depends on several factors: who the actor is, who the other negotiating parties are, and the forum in which negotiations are taking place” (Narlikar 2006: 1005). As experimental evidence shows, agents tend to be influenced by their perception of (un-)fairness. Consequently, decisions of negotiators representing their country in the international climate policy arena tend to be influenced by fairness perceptions which are based on their individual

${ }^{11}$ For an application of different fairness and equity criteria to evaluate the Adaptation Fund, see Grasso (2010). 
country's circumstances and these circumstances (or factors) differ significantly among countries.

Thus, it does not only make much sense to include fairness adjustments in the modelling of international negotiations, but also to investigate how fairness adjustment can be changed in a way that facilitates the attainment of an optimal outcome. International support of climate policy tends to be an attractive tool for this purpose. Adaptation support, for example, could help to correct for perceived unfairness associated with the unequal distribution of individual countries’ past contributions to global warming. By preventing - via adaptation support - that damage costs caused by past emissions materialize in developing countries, these countries' perception of consequence driven (or historical) unfairness could be decreased. Intention driven fairness could be improved by kind behaviour in the present climate policy arena. This concept of fairness is closely related to the concept of procedural fairness. If processes in international climate policy are regarded as 'fair' (which might e.g. be the case when the involvement of all relevant parties in these processes is provided for), then the trust between countries tends to increase and therefore intention driven fairness is improved. This implies a decreasing degree of negative reciprocity and a rising degree of positive reciprocity, making mutual international cooperation in climate protection more likely

In our game-theoretic analysis, fairness concepts do not stipulate but influence the outcomes of international climate policy. We described possible interactions between the different fairness concepts and demonstrated how fairness improvement might change game structures. By referring to the game theoretic analysis, we elaborated the influence international support schemes launched in the past, tend to have on fairness. As we observed, these schemes have not yet fully taken fairness aspects into account, although fairness tends to facilitate the attainment of an effective international climate protection.

There may be several reasons for this seemingly suboptimal level of fairness-generating efforts, e.g. it might be due to a trade-off between fairness-goals and the material wellbeing of transfer providing countries. As we remarked, effective signals for playing 'fair' might be costly in material terms and transfer providing countries will balance cost and benefits of fairness-generating policies. Industrialized countries might also hesitate to more strongly pursue fairness enhancement via climate policy support mechanisms, because they distrust policymakers of individual developing countries and fear that resources might be wasted by these policymakers if they get too easily access to support funds. Such distrust could be reflected by an assignment of the majority of seats in the governing bodies of international 
support funds to industrialized countries. It might therefore be an indication for currently rising trust levels (on the industrialized countries' side) that the majority of the members of the Transitional Committee assigned to design the Green Climate Fund is from the developing world.

\section{References}

Akerlof, G.A. (1979), "The Case against Conservative Macroeconomics: An Inaugural Lecture," Economica, 46, 219-237.

Akerlof, G.A. and Dickens, W.T. (1982), "The Economic Consequences of Cognitive Dissonance," American Economic Review, 72, 307-319.

Albin, C. (2003), "Negotiating International Cooperation: Global Public Goods and Fairness," Review of International Studies, 29, 365-385.

Baron, J. (2006), "Thinking about Global Warming," Climatic Change, 77, 137-150.

Barrett, S. (2008), "Climate Treaties and the Imperative of Enforcement," Oxford Review of Economic Policy, 24, 239-258.

Bird, N.; Brown, J. and Schalatek, L. (2011), Design Challenges for the Green Climate Fund, Climate Finance Policy Brief No. 4, Heinrich Böll Stiftung North America.

Bolton, G.E. (1991), "A Comparative Model of Bargaining: Theory and Evidence," American Economic Review, 81, 1096-1136.

Brennan, G. and Buchanan, J. (1985), The Reason of Rules, Cambridge University Press, Cambridge.

Breton, A. and Dalmazzone, S. (2002), "Information Control, Loss of Autonomy, and the Emergence of Political Extremism," in Political Extremism and Rationality, edited by A. Breton, G. Galeotti, P. Salmon and R. Wintrobe, Cambridge University Press (Cambridge), 44-66.

Buchholz, W. and Peters, W. (2007), "Justifying the Lindahl Solution as an Outcome of Fair Cooperation," Public Choice, 133, 157-169. 
Camerer, C.F. (1997), "Progress in Behavioral Game Theory," Journal of Economic Perspectives, 11, 167-188.

Camerer, C.F. and Thaler, R.H. (2003), "In Honor of Matthew Rabin: Winner of the John Bates Clark Medal, Journal of Economic Perspectives, 17, 159-176.

Carlsson, F.; Kataria, M.; Lampi, E.; Löfgren, Å. and Sterner, T. (2011), "Is Fairness Blind? The Effect of Framing on Preferences for Effort-sharing Rules," Ecological Economics, 70, 1529-1535.

Carraro, C. and Siniscalco, D. (1993), "Strategies for the International Protection of the Environment," Journal of Public Economics, 52, 309-328.

Davidson, C.; Matusz, S. and Nelson, D. (2006), "Fairness and the Political Economy of Trade," World Economy, 29, 989-1004.

Eyckmans, J. and Kverndokk, S. (2010), "Moral Concerns on Tradable Pollution Permits in International Environmental Agreements," Ecological Economics, 69, 1814-1823.

Falk, A. and Fischbacher, U. (2006), "A Theory of Reciprocity," Games and Economic Behavior, 54, 293-315.

Fehr, E. and Gächter, S. (2000), "Fairness and Retaliation: The Economics of Reciprocity," Journal of Economic Perspectives, 14, 159-181.

Gabriele, A.; Boratav, K. and Parikh, A. (2000), "Instability and Volatility of Capital Flows to Developing Countries," World Economy, 23, 1031-1056.

Geanakoplos, J.; Pearce, D. and Stacchetti, E. (1989), "Psychological Games and Sequential Rationality," Games and Economic Behavior, 1, 60-79.

Grasso, M. (2007), “A Normative Ethical Framework in Climate Change," Climatic Change, 81, 223-246.

Grasso, M. (2010), "An Ethical Approach to Climate Adaptation Finance," Global Environmental Change, 20, 74-81.

Hammar, H. and Jagers, S.C. (2007), "What is a Fair $\mathrm{CO}_{2}$ Tax Increase? On Fair Emission Reductions in the Transport Sector," Ecological Economics, 61, 377-387.

Hepburn, C. and Müller, B. (2010), "International Air Travel and Greenhouse Gas Emissions: A Proposal for an Adaptation Levy," World Economy, 33, 830-849.

Kverndokk, S. and Rose, A. (2008), "Equity and Justice in Global Warming Policy," International Review of Environmental and Resource Economics, 2, 135-176.

Kydd, A. (2000), "Trust, Reassurance, and Cooperation," International Organization, 54, 325 357.

Lange, A.; Vogt, C. and Ziegler, A. (2007), "On the Importance of Equity in International Climate Policy: An Empirical Analysis," Energy Economics, 29, 545-562.

Lange, A.; Löschel, A.; Vogt, C. and Ziegler, A. (2010), “On the Self-interested Use of Equity in International Climate Negotiations," European Economic Review, 54, 359-375. 
Messner, D.; Schellnhuber, J.; Rahmstorf, S. and Klingenfeld, D. (2010), "The Budget Approach: A Framework for a Global Transformation toward a Low-carbon Economy," Journal of Renewable and Sustainable Energy, 2, 14 pages.

Müller, B. (2001), "Varieties of Distributive Justice in Climate Change," Climatic Change, 48, 273-288.

Müller, B. (2010), Copenhagen 2009: Failure or Final Wake-up Call for Our Leaders?, Working Paper, EV 49, Oxford Institute for Energy Studies.

Müller, B.; Höhne, N. and Ellermann, C. (2009), "Differentiating (Historic) Responsibilities for Climate Change," Climate Policy, 9, 593-611.

Najam, A.; Huq, S. and Sokona, Y. (2003), "Climate Negotiations Beyond Kyoto: Developing Countries Concerns and Interests," Climate Policy, 3, 221-231.

Narlikar, A. (2006), "Fairness in International Trade Negotiations: Developing Countries in the GATT and WTO," World Economy, 29, 1005-1029.

Paavola, J. and Adger, W.N. (2005), "Institutional Ecological Economics," Ecological Economics, 53, 353-368.

Paavola, J. and Adger, W.N. (2006), "Fair Adaptation to Climate Change," Ecological Economics, 56, 594-609.

Parks, B.C. and Roberts, J.T. (2008), "Inequality and the Global Climate Regime: Breaking the North-South Impasse," Cambridge Review of International Affairs, 21, 621-648.

Pittel, K. and Rübbelke, D.T.G. (2008), "Climate Policy and Ancillary Benefits - A Survey and Integration into the Modelling of International Negotiations on Climate Change," Ecological Economics, 68, 210-220.

Pittel, K. and Rübbelke, D.T.G. (2011), "Transitions in the Negotiations on Climate Change: From Prisoner's Dilemma to Chicken and Beyond," International Environmental Agreements: Politics, Law and Economics, 11.

Rabin, M. (1993), "Incorporating Fairness into Game Theory and Economics," American Economic Review, 83, 1281-1302.

Rabin, M. (1997), Fairness in Repeated Games, Working Paper No. 97-252, Department of Economics, University of California at Berkley.

Rabin, M. (1998), "Psychology and Economics," Journal of Economic Literature, 36, 11-46.

Rawls, J. (1971), A Theory of Justice, Harvard University Press, Cambridge.

Ringius, L.; Torvanger, A. and Underdal, A. (2002), "Burden Sharing and Fairness Principles in International Climate Policy," International Environmental Agreements: Politics, Law and Economics, 2, 1-22.

Rive, N. and Rübbelke, D.T.G. (2010), "International Environmental Policy and Poverty Alleviation," Review of World Economics, 146, 515-543. 
Rive, N.; Torvanger, A. and Fuglestvedt, J.S. (2006), "Climate Agreements Based on Responsibility for Global Warming: Periodic Updating, Policy Choices, and Regional Costs," Global Environmental Change, 16, 182-194.

Rübbelke, D.T.G. (2011), "International Support of Climate Change Policies in Developing Countries: Strategic, Moral and Fairness Aspects," Ecological Economics, 70, 1470-1480.

Stern, N. (2007), The Economics of Climate Change - the Stern Review, Cambridge University Press, Cambridge.

Stiglitz, J.E. (2000), "Two Principles for the Next Round or, How to Bring Developing Countries in from the Cold," World Economy, 23, 437-454.

Suranovic, S.M. (2000), "A Positive Analysis of Fairness with Applications to International Trade," World Economy, 23, 283-307.

Tavoni, A.; Dannenberg, A.; Kallis, G. and Löschel, A. (2011), "Inequality, Communication and the Avoidance of Disastrous Climate Change," Proceedings of the National Academy of Sciences (PNAS), 108.

UNFCCC (2001), Report of the Conference of the Parties on its sixteenth session, held in Cancun from 29 November to 10 December 2010; Addendum: Part Two: Action taken by the Conference of the Parties at its sixteenth session; FCCC/CP/2010/7/Add.1.

Wyplosz, C. (1999), "International Financial Instability," in Global Public Goods International Cooperation in the $21^{\text {st }}$ Century, edited by I. Kaul, I. Grunberg and M.A. Stern, Oxford University Press, New York, Oxford.

Young, O.R. (1989), "The Politics of International Regime Formation: Managing Natural Resources and the Environment", International Organization, 43, 349-375. 


\section{BC3 WORKING PAPER SERIES}

\section{Basque Centre for Climate Change (BC3), Bilbao, Spain}

The BC3 Working Paper Series is available on the internet at the following addresses:

http://www.bc3research.org/lits_publications.html

\section{$\underline{\text { http://ideas.repec.org/s/bcc/wpaper.html }}$}

BC3 Working Papers available (see website for full list):

Luis M. Abadie, Mikel González-Eguino and José M. Chamorro: Optimal Abandonment of Coal-Fired Stations in the EU

Dirk Rübbelke and Stefan Vögele: Impacts of Climate Change on European Critical Infrastructures: The Case of the Power Sector

Roger Fouquet: The Sustainability of 'Sustainable' Energy Use: Historical Evidence on the Relationship between Economic Growth and Renewable Energy

Karen Pittel and Dirk Rübbelke: Energy Supply and the Sustainability of Endogenous Growth

Ramon Arigoni Ortiz, Alexander Golub, Oleg Lugovoy, Anil Markandya and James Wang: The DICER Model: Methodological Issues and Initial Results.

Elena Ojea, Julia Martin-Ortega and Aline Chiabai: Classifying Ecosystem Services for Economic Valuation: the Case of Forest Water Services

Aline Chiabai, Chiara Travisi, Anil Markandya, Helen Ding, and Paulo Nunes: Economic Assessment of Forest Ecosystem Services Losses: Cost of Policy Inaction

Kaysara Khatun: Competing Ecosystem services: an Assessment of Carbon and Timber in the Tropical Forests of Central America

Karen Pittel and Dirk Rübbelke: Local and Global Externalities, Environmental Policies and Growth Change: A Survey of Recent Quantitative Research

2010-17 Luis Mari Abadie, Ramon Arigoni Ortiz and Ibon Galarraga: The Determinants of Energy Efficiency Investments in the U.S.

2010-18 Aline Chiabai, Dirk Rübbelke and Lisa Maurer: ICT Application in the Research for Environmental Sustainability

Roger Fouquet: Long Run Dynamics of Energy-Related External Costs and Fairness Aspects 